GLOBAL JOURNAL OF EDUCATIONAL RESEARCH VOL 15, 2016: 1-6 COPYRIGHT@ BACHUDO SCIENCE CO. LTD PRINTED IN NIGERIA. ISSN 1596-6224

\title{
TEACHING MATHEMATICS CREATIVELY IN THE JUNIOR SECONDARY CLASSES
}

\section{FELIX O. UWAEZUOKE AND GLADYS CHARLES-OGAN}

(Received 22, September 2015; Revision Accepted 13, October 2015)

\begin{abstract}
This paper tried to emphasize the importance of teaching mathematics with creativity in the Junior Secondary classes (JS1-3) of our education system. It was established that a mathematically creative environment like the mathematics laboratory will enhance the teaching and learning of mathematics in schools. In this study, few examples of creative lessons in mathematics based on experimenting, experiencing, hands-on activities and collaboration was given, the implication of mathematics creativity stated and appropriate recommendations proffered.
\end{abstract}

KEY WORDS: creativity, mathematically creative environment and mathematics laboratory.

\section{INTRODUCTION}

Several contemporary scholarly reports are replete with clear evidence of the overall importance of mathematics as a school subject with respect to its role as a foundation for nation building, utility base for daily living and service to other disciplines etc (Roohi, 2014; Ogunkunle, 2002; Awoyemi, 2007; Uwaezuoke, 2013 etc). The United Nations Educational, Scientific and Cultural Organization (UNESCO) which is the education arm of the United Nations, in recognition of the importance of mathematics, promotes mathematics education globally especially in developing countries. The organization supports activities that address the lack of interest by students in mathematics and those that aim at sensitizing teachers on both their knowledge of new developments in mathematics as well as its significance to society (UNESCO, 2014).

In line with UNESCO's global mathematics education campaign, many countries now mandate the teaching of mathematics as a core subject at the primary and secondary levels of their education system to ensure universal mathematics literacy. Pound and Lee (2011) summated that mathematics literacy which is the capacity to identify, understand and engage in mathematics and make well-founded judgments about the role that mathematics plays, as needed for an individual's current and future private life, social life with peers and relatives, and life as a constructive, concerned and reflective citizen is an indispensible need for every individual.

The importance accorded mathematics notwithstanding; many students in the Junior Secondary level still find it difficult to cope with the subject. Though some of these students may exhibit traits of interest in mathematics; it is clearly evident that the teaching and learning process is still void of the experiences, innovations and creativities needed to jolt and motivate their young and energetic minds into exploring the vast field of mathematics (Pound and Lee, 2011; Back, 2014). The Junior Secondary level is the stage were students ought to make meaning of mathematics, its usefulness to life and application to further studies. It is the

Felix O. Uwaezuoke, Department of Curriculum Studies and Educational Technology, Faculty of Education, University of Port Harcourt, Port Harcourt. Nigeria.

Gladys Charles-Ogan, Department of Curriculum Studies and Educational Technology, Faculty of Education, University of Port Harcourt, Port Harcourt. Nigeria. 
stage where decision to pursue mathematics related subjects and career in future is made; hence teaching and learning of the subject with creativity, experiments and hands-on activities becomes were crucial. This is to avoid pushing the career decisions of these young learners to hinge on bias and of course, regrets.

\section{Creativity in mathematics teaching and learning}

According to the Longman Dictionary of Contemporary English, to be creative means to produce or use new, varying and effective ideas, hence arriving at better results. Creativity in a mathematics classroom will include the production and use of new, varying and effective ideas by both teacher and students to improve the outcomes of mathematics teaching and learning (Piggot, 2014).

Mathematical creativity is an ability to analyze a given problem from different perspectives, see patterns, differences and similarities, generate multiple ideas and choose a proper method to deal with unfamiliar mathematical situations. The mathematics teacher needs to explore creative and innovative avenues in the mathematics classroom and also allow students to do likewise in the face of new challenges. The experience of creative mathematics of the teachers themselves plays a vital role in introducing creative mathematical activities for development of mathematical thinking in the classroom. It is important therefore, to lay emphasis on the training of teachers in ability to design and implement educational environment that promote creativity in mathematics. Also, students should be given ample opportunities to explore the hidden creative tendencies in themvia opportunity to learn to search, explore, make conjectures, hypothesize, examine, refute, adapt strategies, device plans, reason, conclude, justify conclusions, reflect, monitor and experience the processes that mathematics has gone through at the guidance of the teacher. In a mathematically creative environment as above, the place of collaboration becomes a vital issue; as team work, exchange of ideas and sharing of creative thoughts is inevitable (Nadjafikhah, Yaftian and Bakhshalizadeh, 2012; Haylock, 1987; Idris and Nor, 2010; Steiner, 2000).

The mathematics teacher, when approaching a proposed topic for a lesson, reflects on all innovative and creative ways through which he and the learners can make the best of the learning process and achieve set objectives. In doing this, he looks out for those materials which can be harnessed from the environment which the learners are already familiar with, past experiences of both teacher and learners which could lead to better perception of the new knowledge, activities which would get learners involved and hence sustain their interest, and of course, guide learners discover the mathematical facts and ideas themselves.

\section{The mathematics laboratory; a creative mathematics environment}

The ideal platform for mathematical creativity and enhanced student-student and/or teacher-student collaboration is a mathematics laboratory. The mathematics laboratory is a unique room or hall, with relevant and up-to-date equipment and instructional materials, designated for the teaching and learning of mathematics and other scientific work or research whereby professionally trained personnel (teacher) interacts with learners on specific sets of instructions. Put differently, it is a place where students can learn and explore mathematical concepts and verify mathematical facts and theorems through a variety of activities using different materials (Adenegan, 2014; Central Board for Secondary Education (CBSE), 2014).

A mathematics laboratory contributes to learning in the following ways;

* It provides an opportunity for students to internalize basic mathematics concepts through concrete objects and situations.

* It enables the students to verify or discover several geometrical properties and facts using models or paper cutting and folding techniques.

* It helps the students to build interest and confidence in learning the subject.

* The laboratory provides opportunity to exhibit the relatedness of mathematical concepts with everyday life.

- It provides greater scope for individual participation in the process of learning and becoming autonomous learners,

- It provides scope for greater involvement of both the head and the hand which facilitates cognition.

* The laboratory allows and encourages students to think, discuss with each other and with the teacher, and assimilate concepts in a more effective manner. 
* It encourages the teacher to demonstrate, explain and reinforce abstract mathematical ideas by using concrete objects, models, charts, graphs, pictures, posters etc (CBSE, 2014).

Adenugannoted that though the benefits of a mathematics laboratory are enormous, it is still a strange phenomenon in many parts of subSaharan Africa. For a few schools where a mathematics laboratory is recognized, it is usually a corner of a classroom with a few student-made geometric shapes, charts and models. But the actual idea is to bring learners into a complete mathematics world where mathematical facts and ideas can be tested and verified hence exploring their creative tendencies and arousing their interest in the subject.

A typical mathematics laboratory should be in a dust-free hall with adequate ventilation and electricity. Learning materials should include all the student-made instructional materials, mathematical kits from the National Mathematics Center (NMC, Abuja), and Information and Communication Technological (ICT) teaching tools that can enhance mathematics learning.

\section{Some creative lessons in mathematics (which are most suitable in the laboratory)}

\section{Example 1}

Topic: Pythagoras theorem

Theorem: The area of the square on the hypotenuse of a right-angled-triangle is equal to the sum of the areas of the squares on the other two sides (ie $b^{2}=a^{2}+c^{2}$ ).

Objective: Verification of Pythagoras theorem by the method of paper folding, cutting and pasting.

\section{Previous knowledge:}

1. Students are familiar with the concept of area of a square.

2. They can construct a right-angledtriangle, take simple measurements, cut and paste paper.

Materials required: Cardboard paper, pencils, mathematical sets, gum and pair of scissors.

\section{Procedure:}

1. Take a normal size cardboard.

2. Construct a right-angled-triangle $A B C$ on the cardboard with sides a, b, c, and b as the hypotenuse.
3. Form a square on each side such that the length of the sides of the square is equal to the length of the particular side of the triangle.

4. Cut out the squares on sides $a$ and $c$.

5. Divide each square into unit squares and cut out.

6. Gather all the unit squares and carefully place them orderly inside the square on side $b$ of the right-angled-triangle.

\section{Observation:}

The unit squares cut from the squares on side a and $\mathrm{c}$ of the right-angled-triangle completely fill the square on side $b$ of the same triangle, thus verifying the Pythagoras theorem and establishing students' cognition. The seemingly abstract mathematical identity $b^{2}=a^{2}+c^{2}$ can be simplified through a creative mathematics lesson.

\section{Example 2}

Topic: Area of a rectangle.

Definition: The area of a rectangle is the number of unit squares contained in it.

Objective: Deriving a formula for the area of a rectangle.

\section{Previous knowledge:}

1. Students are familiar with rectangles.

2. They can measure, cut and paste paper.

Materials required: Cardboard paper, scissors and mathematical sets.

\section{Procedure:}

1. Draw a rectangle of any size on the cardboard paper (say $8 \mathrm{~cm}$ by $6 \mathrm{~cm}$ ).

2. Mark each side at $1 \mathrm{~cm}$ interval and join a perpendicular from each mark to the opposite side.

3. A network of $1 \mathrm{~cm}$ by $1 \mathrm{~cm}$ unit squares is formed.

4. Count the number of unit squares and take note. This is the area of the rectangle.

5. Now multiply the length and width used as scale for drawing and take note of the result (say $8 \mathrm{~cm} \times 6 \mathrm{~cm}=48 \mathrm{~cm}^{2}$ ).

6. Compare the results of (4) and (5) above, are they similar or different?

7. If the two results are similar, then the formula for the area of a rectangle is given by the multiple of the length and the width $(\mathrm{I} \times \mathrm{w})$ in square units which is equal to the number of unit squares contained in it as defined. 


\section{Observation:}

The formula for the area of a rectangle as derived by learners themselves is internalized and appreciated.

\section{Example 3}

Topic: Circumference of a circle.

Definition: this is the distance round the circle. Objectives: Finding a value for $\mathrm{Pi}$, hence deriving a formula for the circumference of a circle.

\section{Previous knowledge:}

1. Students are familiar with circles.

2. Students can take simple measurements.

\section{Requirements:}

1. Students were asked to find circularbased objects, draw out the circularbase on a cardboard paper, cut them out and bring the cuttings to class for the practical lesson.

2. Thread, exercise book, pen or pencil, mathematical set and a calculator.

\section{Procedure:}

1. Pick one of your cut out circles and mark a point on the edge.

2. Place your thread on the mark and measure round the edge of the circle until you return back to the mark.

3. Measure out the length of the thread on a meter rule and take your reading. This is the circumference $\mathrm{C}$ of the circle.

4. Mark a point $O$ at the center of the circle. Place a meter rule to measure from one edge of the circle through the center $\mathrm{O}$ to the opposite side of edge in a straight line and take your reading. This is the diameter $\mathrm{D}$ of the circle.

5. Find the ratio of the circumference $C$ to the diameter $\mathrm{D}$ (that is $C / D$ ) and take note.

6. Compare the result in (5) above of all the students with circles of different sizes. All their results tend to a constant $22 / 7$ or 3.142. This constant is called $\mathrm{Pi}$ denoted

7. It has been shown in (6) above that $C / D$ $=$, where $\mathrm{C}=$ circumference, $\mathrm{D}=$ diameter and $=\mathrm{Pi}$.

Making $C$ the subject of the formula, we have;

$\mathrm{C}=\mathrm{D}$
But the distance from the center $O$ of the circle to the edge is equal to a radius $R$. Hence, a diameter $\mathrm{D}=2 \mathrm{R}$.

Thus we can write;

$$
\mathrm{C}=(2 \mathrm{R}) \rightarrow 2 \mathrm{R}
$$

Therefore the circumference $\mathrm{C}$ of a circle is derived as;

$$
\mathrm{C}=2 \mathrm{R} \text { or } \mathrm{D}
$$

8. Multiply the value of pie with the result of diameter in (4) above and compare it with the result of (3) above.

\section{Observation:}

The results are the same for each particular circle in step (3) and (8). Students can conveniently use the formula for circumference of a circle to compute and will also be familiar with the derivation of the value of the constant $\mathrm{Pi}$.

\section{Creative steps taken during the lessons}

* Opportunity would be given to students to internalize basic mathematics concepts through concrete objects and situations.

* Students would be able to verify and discover several mathematical properties and facts using models or paper cutting and folding techniques.

* Students could build interest and confidence in learning the subject since ample opportunities would be provided to exhibit the relatedness of mathematical concepts with everyday life.

* A greater scope for individual participation in the process of learning and becoming autonomous learners would be provided.

* There would be provision for greater involvement of both the head and the hand which facilitates cognition.

* The processes would allow and encourage students to think, discuss with each other and with the teacher, and assimilate concepts in a more effective manner.

* There would be ample opportunity for the teacher to demonstrate, explain and reinforce abstract mathematical ideas by using concrete objects and models.

\section{Implication for mathematics teaching and learning}

Lack of interest, phobia and subsequent failure in mathematics has been the bane of many 
students at the secondary level of our education system. This is a clear pointer to the fact of an error in classroom delivery of mathematics as a subject in our schools. An abstraction is created when teachers do not lead learners to discover mathematical facts through simple creativity (harnessing the environment, partaking in simple activities and discovering of simple mathematical facts themselves), it becomes difficult for them to understand that these facts emanate from our daily operations and activities, and are designed to improve our daily functionality.

Creative teaching of mathematics therefore is the panacea to this problem; since teacher and student creative participation is guaranteed and of course, the knowledge learners create by themselves are internalized thus sustaining their interest and improving their performance in the subject.

\section{RECOMMENDATIONS}

Based on the expositions of this work, the researcher recommends thus;

* Mathematics teachers are called upon to seek for creative ways to drive home each slated topic, starting from the given materials to improvisation and harnessing of the environment.

* Forthwith, the building and equipment of mathematics laboratories in schools should be embarked on by the government.

* Finally, teacher education programs should include creative teaching of mathematics, while in-service training should be organized for serving teachers to keep them abreast of the necessity and know-how.

\section{REFERENCES}

Adenegan, K. E., 2014. Setting Mathematics Laboratory in Schools. Retrieved On04/04/2014from www.directorymathsed.net/download/Ad enegan.pdf

Awoyemi, D. O., 2007. Mathematics: The exact science for nation building. Retrieved on02/04/2014 from www.dspace.futa.edu.8080/.../maths

Back, J., 2014. Creative Approaches to Mathematics across the Curriculum.
Retrieved on02/04/2014

from www.nrich.maths.org/4770

Central Board of Secondary Education (CBSE), New Delhi 2014. Guidelines For Mathematics Laboratory in Schools: Class $X$. Retrieved on 04/04/2014fromwww.cbse.nic.in/mathlab. pdf

Haylock, D. W., 1987. A framework for assessing mathematical creativity In school children. Educational Studies in Mathematics; 18 (1), 59-74.

Idris, N. and Nor, N. M., 2010. Mathematical creativity: usage of technology. Procedia: Social and Behavioral Sciences (ISI/SCOPUS cited publication.

Nadjafikhah, M; Yaftian, $\mathrm{N}$ and Bakhshalizadeh, S., 2012. Mathematical Creativity: somedefinitions and characteristics. Retrieved on 04/04/2014 fromwww.sciencedirect.com/science/artic le/pii/s1877042811029855

Ogunkunle, R. A., 2002. Innovations in the training of mathematics teacher for Sustainable development in the $21^{\text {st }}$ century. Eastern COEASU Journal of Teacher Education; September, 2002: 1 (1).

Piggot, J., 2014. Cultivating Creativity (maths). Retrieved on 02/04/2014 from www.nrich.maths.org/5784

Pound, L and Lee, T., 2011. Teaching Mathematics Creatively. Retrieved on 03/04/2014 from:www.amazon.com/Teac hing-Mathematics-creatively

Roohi, F., 2014. Role of Mathematics in the Development of Society. Retrieved on03/04/2014 from www.ncert.nic.in/.../Find-ArticleRole\%20of\%20mathematics\%20in\%20

Steiner, J., 2000. Creative Collaboration. Oxford; Oxford University Press. United Nations Educational, Scientific and Cultural Organization (UNESCO), (2014). Mathematics Education. Retrieved on 05/04/2014 
www.unesco.org/new/en/.../.../scienceeducation/.../mathematics
Uwaezuoke, F. O., 2013. Curriculum Innovation in Mathematics for the Achievement of the Millennium Development Goals in N igeria. Proceedings of the $54^{\text {th }}$ Annual Conference of Science Teachers

Association of Nigeria (STAN); No 4, pp 25-30. 